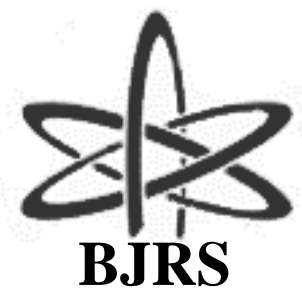

BRAZILIAN JOURNAL

$\mathrm{OF}$

RADIATION SCIENCES

09-02A (2021) 01-20

\title{
The importance of probabilistic safety assessment in the study of risks involved to new nuclear power plant projects
}

\author{
Mata $^{a}$ J.F.C, Mesquita ${ }^{\mathrm{a}}$ A.Z. \\ ${ }^{a}$ Centro de Desenvolvimento da Tecnologia Nuclear/Comissão Nacional de Energia Nuclear (CDTN/Cnen). Serviço de \\ Radiofármacos e Irradiações (Serfi). CEP 31.270-901, Belo Horizonte, MG, Brasil \\ jonatasfmata@yahoo.com.br
}

\begin{abstract}
The Fukushima Daiichi nuclear accident in Japan in 2011 has raised public fears about the actual safety of nuclear power plants in several countries. The response to this concern by government agencies and private companies has been objective and pragmatic to guarantee best practices in the several phases of nuclear reactors. In countries where the nucleoelectric matrix is consolidated, such as the United States, France and the United Kingdom, the safety assessment is carried out considering deterministic and probabilistic criteria. In the licensing stages of new projects, it is necessary to analyze and simulate the behavior of the nuclear power plant, when subjected to conditions that can lead to sequences of accidents. Probabilistic Safety Assessment (PSA) is fundamental in this process, as it studies in depth the sequences of events that can lead to damage to the reactor core. Such sequences should be quantified in terms of probability of occurrence, the possible consequences organized through techniques such as Fault Tree Analysis and Event Tree Analysis. The present work will describe the procedures for the realization of PSA and its applicability to the assurance of the operational reliability of the nuclear reactors, as well as a brief comparative between the approaches used in some countries traditionally users of thermonuclear energy and Brazil. By means of this analysis, it can be concluded that nuclear power is increasingly reliable and safe, being able to provide the necessary tranquility for the population of the countries where it is inserted.
\end{abstract}

Keywords: Probabilistic Safety Assessment, nuclear power plant, reliability, operational safety, nuclear risk. 


\section{INTRODUCTION}

The nuclear accident at the Fukushima Daiichi plant on March 11, 2011, following an earthquake and tsunami, is considered one of the most severe accidents at nuclear power plants. The immediate actions to contain the consequences of the accident, as well as the unfolding of preventive actions obtained through the lessons learned, have brought about an intense movement of the countries that use the nucleoelectric matrix. The regulatory authorities of these nations have been organizing to establish common guidelines and procedures to make nuclear power stations safer and more reliable. In this interim, the main focuses are [1]:

a) reassessment of external risks;

b) improvement of the robustness of the electrical systems;

c) improved protection of the containment structures of the reactor;

d) safety of irradiated fuel storage pools;

e) increasing the capacity of emergency energy supply systems;

f) reinforcement in equipment and teams for emergency preparedness on and off the site;

g) recycling of the safety culture, with the study and improvement of human and organizational factors;

h) continuous safety audit.

The Fukushima event reinforces the need to developing robust and highly reliable risk assessments.

Despite the finding of flaws in the project and emergency and safety systems, human and organizational factors that contributed to the Fukushima nuclear accident have be found. According to the official investigation conducted by an independent commission led by Kurokawa [2], there were organizational failures committed by the Japanese government, regulatory agencies and the company TEPCO company, responsible for the operation, as well as errors in leadership and management in these instances. Therefore, it would not be correct to attribute the blame to a single individual or group of people, but to wrong decisions and actions by organizations responsible for the management and safety of the Fukushima Daiichi nuclear power plant. 
According to TEPCO company, the accident was caused by a tsunami of unpredictable dimensions. However, both the operator and regulatory authorities were aware of the risks of a tsunami and an earthquake. There have been, on certain occasions, the possibility of implementing preventive measures to increase the safety of the nuclear units in Fukushima, such as the construction of higher barriers and resistant to tsunamis, but nothing has been done [2].

Gisquet and Older [3], in turn, analyzed the actions and behaviors of the operating teams of the Fukushima nuclear power plant, and brought important conclusions about possible human and organizational failures committed during the accident. The conditions and circumstances were, in general, quite different from those found in the working manuals. This fact brought responses defined by individual decisions or by the team, subject to adverse conditions, such as: little time available for planning; insufficient resources; instrumentation and automation sensors in failure mode. Considering these problems and, as an aggravating factor, the imminent risks of radioactive contamination and personal accidents, it was possible to verify that the operators managed their actions satisfactorily. There was even a good level of reinforcement of collective values and the maintenance of the hierarchical structure in the definition of the activities defined for the supervisor and his team. However, insufficient knowledge and operational practice, in relation to emergency systems and the diversity of types of reactors, brought losses to the faster and more robust resolution of the problems that occurred.

The questions posed above, referring to serious organizational and human failures, are arguments that reinforce the need to use the PSA methodology to bring robustness to nuclear plants, allowing the people involved to know the risks involved and manage them properly. Management and human behavior issues are essential for reducing the risks of nuclear accidents [3].

This scope is obtained through Probabilistic Safety Assessment (PSA), where several techniques are combined to evaluate events and failures, such as external events, common-cause failures and human errors [4]. The present work presents the main concepts and peculiarities involved in the realization of a PSA directed to nuclear reactors.

\section{MATERIALS AND METHODS}


The present article conducts a meticulous bibliographical research, a qualitative about the methodologies used in PSA, where the main concepts and their importance are presented and organized in topics. In this research, is displayed a qualitative comparison of the use of PSA in countries with consolidated nucleoelectric generation (United States of America (USA), France, United Kingdom (UK) and Canada) besides Brazil is displayed. This survey was acquired during undergraduate studies of the author, the master degree level.

\section{RESULTS AND DISCUSSION}

\subsection{Risk and its Application in PSA}

Risk can be defined as a combined answer of three questions [5]: a) What can fail? b) In what way, expressed in frequency, can the fault occur? c) What are the possible consequences of failure? The study of the risks involved in the design, construction, operation and decommissioning of a nuclear power plant is developed through Quantitative Risk Analysis (QRA). QRA is considered an evolution of traditional approaches to risk investigation and treatment, based previously on deterministic premises and, therefore, concerned to evaluate and quantify only the consequences of the accident scenarios provided in Design Bases Accident (DBA). QRA therefore uses probabilistic methodologies to estimate the frequency of occurrence and consequences of accident scenarios under conditions described in DBA and Beyond the Design Bases Accident (BDBA). In this interim, QRA acts in a complementary way to deterministic approaches [6].

\subsection{Scope and Types of PSA}

PSA is an important methodology for the identification, evaluation, estimation and management of risks related to the safety of buildings, facilities and people involved in the various stages of nuclear projects, such as: design; construction; operation; maintenance; and decommissioning. PSA provides the achievement of fundamental objectives for nuclear reactors, such as: 
a) quantification of the Core Damage Frequency (CDF), which means the calculated frequency at which the nuclear reactor can undergo partial or complete melting if the heat generated is not sufficiently removed during operation or shutdown;

b) identification of the main sequences of possible accidents; c) study of components and systems subject to failure; d) parameterization of computerized models that allow the control, instrumentation and management of operational system; e) base for project modifications [7].

PSA has three levels of evaluation, as follows:

a) PSA level 1: directed to the study and estimation of the risks involved in the sequences of accidents that can cause damage to the reactor core. Estimates are therefore quantified in terms of CDF;

b) PSA level 2: from the accident sequences described in PSA level 1, quantifies the risks involved in the release of radioactive emissions from to the nuclear reactor core;

c) PSA level 3: quantifies the consequences of radioactive emissions to the public, workers and the environment [8]. Figure 1 shows the interrelation between the three levels of PSA.

\section{$\underline{\text { PSA level } 1}$}

PSA Level 1 evaluates the sequences of events that have the probability of causing damage to the reactor core. In this process, the strengths and weaknesses of the systems involved are identified, thus defining preventive and corrective actions to eliminate or minimize the occurrence of severe accidents. This phase is responsible for the identification and selection of plant data, in order to make the selection and categorization of possible initiating events.

The initiating events should be grouped according to common characteristics, such as: progression of the accident from the initial event; acceptance criteria for control and mitigation systems; effect of each initiating event on the availability and operational safety of the reactor; types and characteristics of required safety systems, including alarms and actuations controlled by instrumentation and automation; and expected responses from operators [9]. 


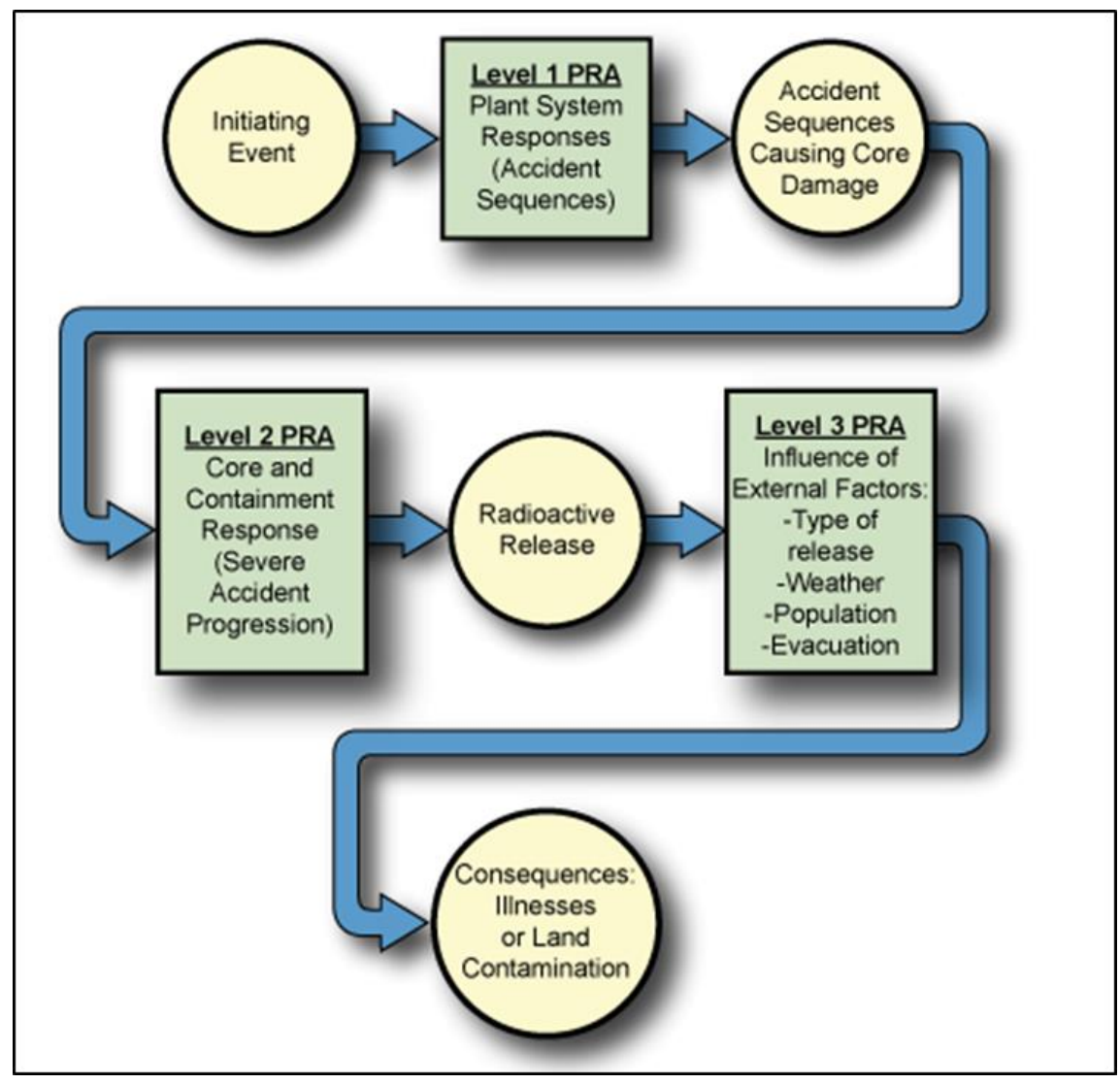

Figure 1: Relationships between PSA levels 1, 2 and 3. Source: NRC (2019) [8]

Some important techniques are used to structure the simulation of the sequences of accidents. Among these, we highlight the methodologies of Event Tree Analysis (ETA) and Fault Tree Analysis (FTA). ETA is the graphical representation of one or more accident scenarios, which usually occur from an initiating event. It develops according to a sequence of events, considering different scenarios, depending on the success or failure of certain functions of the activity or installation. In such diagrams, active safety systems intended to block or minimize the progression of failures should be considered [5]. In turn, FTA is a graphical representation of a sequence of events in reverse order of normal occurrence. It starts from an undesirable result or a failure, with the unfolding of the events causing these failures. The objective, in this case, is the identification of the events causing these failures. Such a process is systematically conducted in several steps, until, at the end, the initiating event or the root cause is obtained [10]. Figure 2 schematically shows a 
FTA initiated from the problem of loss of power supply, and Figure 3 shows an ETA where an initiating event is deployed in a sequence of events [11].

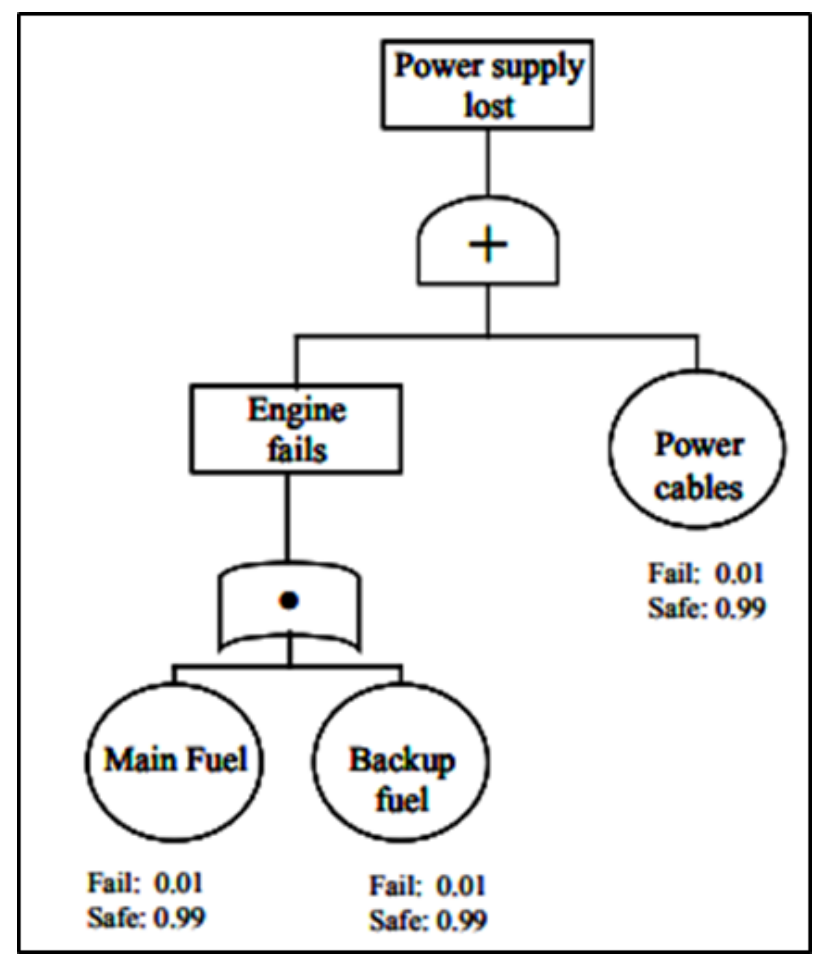

Figure 2: FTA for power supply lost. Source: Faber (2001) [11]

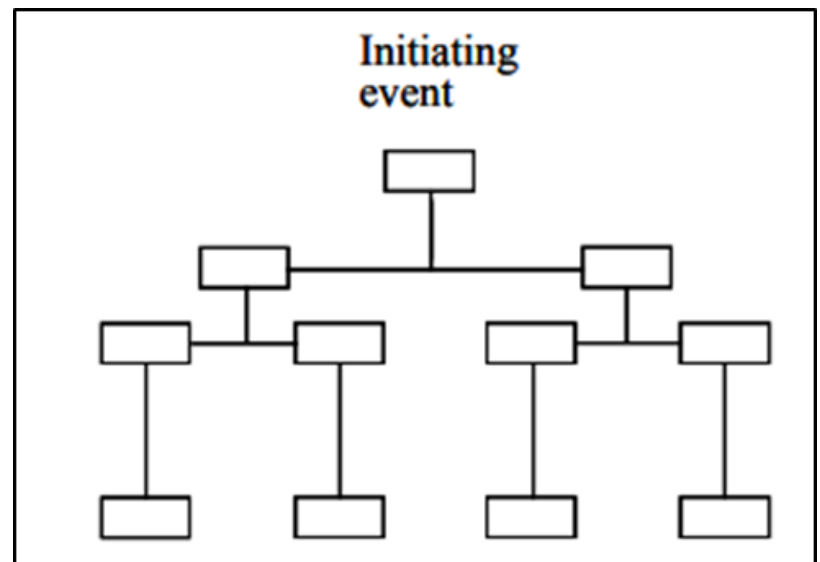

Figure 3: ETA for generic initiating event. Source: Faber (2001) [11] 
Previously, PSAs for NPPs were targeted at a specific unit. After the Fukushima Daiichi nuclear accident, the importance of considering the risks involved with several units at the nuclear power plant sites was highlighted. Therefore, it can be considered that this change in methodology is one of the innovations resulting from the lessons learned from this accident. The development of PSAs targeting the risks involved in more than one nuclear unit has been essential for countries such as Korea, Canada, Japan, China and India, where NPPs tend to have six or more operational units. The analysis of the risks involved in several nuclear units considers initiation events caused by internal problems, floods and fires, in addition to external events such as earthquakes, tsunamis or typhoons [12].

\section{$\underline{\text { PSA level } 2}$}

The PSA Level 2 consists of the analysis of the chronological progression of the damage sequences to the reactor core, in order to identify the different relations between the possible undesirable events in the reactor and adjacent installations. In this way, they add new data on the frequencies and consequences of damages, including radioactive releases to the environment. The main characteristics of the nuclear power plant under study, capable of influencing the progression of severe accidents (accidents that may lead to partial or complete melting of the reactor core), should be identified and characterized. Some of these characteristics may be exemplified: pressurized area of the reactor (flow of the molten material of the core, in proportion to its flow through the lower part of the reactor pressure vessel, extension and cooling of the molten material under certain pressure and temperature conditions); and configuration of the containment (if compartmentalized, will limit the extent to which the combustible gas mixture spread) [13].

For the damage states of the plant, the containment status should be characterized, as follows: intact and isolated; intact and not isolated; in fault mode; or in situations of loss of confinement effectiveness. In case the confinement is not effective, it is necessary to specify the type and size of the deviation, involving issues such as: loss of coolant in interface systems; and rupture of steam generator tubes. The containment of a nuclear reactor is a physical structure, with the property of withstanding various types of damage to the core of the reactor and, thus, retaining a large amount of radioactive material. Therefore, the evaluation of containment responses should result in an objective characterization of possible containment failures generated by severe accidents, 
considering the release of radionuclides into the environment. This study requires the identification and analysis of detailed information on the structural design of the confinement [13].

ETA has become an important tool used in the sequencing of events and phenomena related to severe accidents. Such accidents can cause significant damage to the reactor core, challenging the successive layers of barriers built to eliminate the risks of release of radioactive material. These ETAs, which allow a careful evaluation of the nuclear power plant resistance against severe accidents, are called Containment Event Trees [13].

Once the simulations and estimates of the key variables present in the progression of the accident sequences have been performed, the calculation of the source term associated with the final states of the Containment Event Tree must be conducted. The source term determines the amount of radioactive material released from the nuclear power plant to the environment. Such source terms should be grouped into release categories according to their final states. To characterize such release categories, sets of attributes must be specified, which evidence the transport mechanisms of radioactive materials and possible containment failures. Some examples of attributes can be given as follows: time elapsed from the beginning of the accident to the release of radiation; pressure of the reactor vessel during core damage; mechanism and containment leakage modalities; active devices for capture of radioactive material; and passive devices for capture of radioactive material [13].

The grouping of the final states is usually performed by specific computer codes for this purpose, according to criteria regarding the release of radioactive materials. At the end of this step, we will have an organized map of the groups of final states of the Containment Event Tree, classified in terms of radiological release and consequences external to the reactor. The source terms and frequencies of the release categories should be used to determine the Large Release Frequency (LRF) and the Large Early Release Frequency (LERF). The LRF represents the frequency of an extensive and rapid emission of radiation in the air from fission products in a nuclear reactor. In this process, the emission is released from its confinement to the environment, and it is assumed that there will be time to perform actions to avoid exposures above the limit for the environment and individuals. On the other hand, the LERF consists of the frequency of an extensive and rapid emission of radiation in the air from fission products, before effective actions are taken to protect the environment, workers and the public. That is, the LERF considers the 
estimate frequency in case of not succeeding in the actions of elimination or minimization of the effects of radiation [8].

\section{PSA level 3}

The PSA Level 3 studies are directed to the probabilistic evaluation of the consequences of radionuclide release at sites outside the nuclear reactor. The main entries of Level 3 PSA can be illustrated below: amounts of radiation to be released in severe accidents provided by APS Level 2; release frequencies of radionuclides, expressed in LRF and LERF; release forms and likely release sites; meteorological surveys; population data; and economic analysis. The typical outputs of a Level 3 APS may include: collective doses of radiation; effects on people's health (deterministic and probabilistic); economic impacts; and effects on local and regional farming [14].

With respect to meteorological aspects, it is known that the main form of propagation of nuclear fission products, after a severe accident, is the transport and diffusion of radionuclides through the air. Considering the models available for atmospheric dispersion studies, the Gaussian Pen model stands out due to its simplicity, low costs and simpler calculations. This methodology considers a Gaussian distribution, and the transport is represented by linear vectors. Atmospheric diffusion models require, for their elaboration, a large amount of historical meteorological data. Such databases will make it possible to define representative probability distributions in event propagation simulations [14].

However, the Gaussian model involves conservative methodologies, whose success is recognized in only median scales (2 to $2000 \mathrm{~km}$ in length). In addition, they are based on welladjusted parameters and under previously defined weather conditions. Because they do not model flow equations directly, they are ineffective in simulating air currents generated by adverse conditions, such as: presence of buildings; sudden changes in ambient temperature; interactions with the terrain; and convection flows formed by radioactive releases. The Computational Fluid Dynamics (CFD) code is an interesting alternative, as it makes it possible to include the conditions mentioned above, in addition to simulating the evolution of the plume according to parameters such as: release temperature, wind speed, size and location of the emission source [15].

After the Fukushima nuclear accident, government regulatory authorities have demanded, for the implementation of new nuclear power plants, increasingly broad and accurate modeling of the 
consequences of possible collapse of this type of enterprise. Nicolici et al. [16] developed comparative studies of the simulation of radioactive emission flows in the event of a nuclear accident, considering two different approaches: CFD and Gaussian Puff. In these scenarios, uncertainties were added to the model, caused by factors such as: source intensity, dispersion model or meteorological input data. It was found that the CFD model showed greater reliability and precision than the Gaussian model, especially when extreme weather conditions are considered.

PSA Level 3 should consider, for each severe accident, comprehensive emergency plans for the protection of the public and the environment. Regulatory agencies should conduct periodic reviews of these plans in order to ensure integrated actions between the licensed company and government agencies. The following are some activities that should be simulated and communicated: fire and explosion control; plans for banning affected areas and withdrawing individuals; care for accident victims; procedures in case of emergencies caused by natural events such as floods, tsunamis and earthquakes; and other actions [14].

The degree of exposure of individuals to radiation is proportional to several factors, such as: proximity to radioactive sources; duration and intensity of exposure; types of radionuclides present; release physical condition; and presence or damage of protective barriers. Analysis of the effects of radiation on human health requires detailed studies of stochastic (for example, cancer) and deterministic (burns, for example) effects. There are determining factors for the intensity and type of adverse health effects, such as: dose value received; type of radionuclide; exposure time; form of exposure (oral, skin or other type of route); and affected organs. The probabilities and consequences are also dependent on the size of the population affected and other factors [17]. About economic activities, adverse effects may occur due to impacts caused by severe accidents. In the case of emissions of radionuclides to the environment, there is a need to evacuate several locations, such as: housing and commercial quarters; industrial centers; areas of cultivation and animal husbandry; and other locations. The costs related to evacuation should be quantified in relation to: financial losses of companies and the local economy; unemployment and the economic difficulties of those affected; costs of relocating the population and reconstruction of affected sites; and other costs [17]. 


\subsection{The Fukushima Nuclear Accident and the Use of PSA}

On March 11, 2011, a nuclear accident struck reactors 1, 2 and 3 of the Fukushima I Daiichi Nuclear Power Plant located in Japan. The Fukushima nuclear accident was classified as level 7, according to the International Nuclear Events Scale (INES). The Tohoku earthquake, whose epicenter was about $70 \mathrm{~km}$ north of Japan, brought high vibrations at the bases of the aforementioned reactors. The automatic shutdown system was actuated, and then the power cables were broken. The emergency generators were connected for reactor core cooling. However, after four minutes of the earthquake, a 14-meter-high tsunami swept through the sea, over the protection wall, flooding the plant and generating a complete stop of the cooling. This led to the melting of the core of the reactors 1,2 and 3 and the release of large quantities of fission products into the environment. Evacuation of thousands of people was carried out in the surroundings, with no damage to the health of the evacuated population [18].

Can be cited some important initiatives, derived from the lessons learned from the Fukushima accident: working with more rigorous criteria for probabilistic studies aimed at severe accidents; height increase of the protective walls of nuclear power plants, in regions subject to earthquakes and tsunamis; redefining the location and operating system of external power supply equipment, such as batteries and generators; implementation of high water reservoirs for cooling, with a trip that is independent of electric energy (water release by gravity, in emergency situations); improvement of the risk management of accidents; and creation of command center for emergency response [18].

The methodologies used in the design of new nuclear power plants have been more restrictive and complex, being extremely strict in the joint use of in-depth defense criteria and probabilistic safety techniques. In addition, the study of the progression of severe accidents from external events has been emphasized. Extreme consequences have been considered, such as the release of large quantities of radionuclides into the atmosphere and liquid effluents, with appropriate simulation of emergency plans capable of mitigating human exposures to released radiation [18].

Therefore, the demand for PSA studies to ensure reactor safety, under BDBA conditions, has been strengthened by most of the nuclear regulatory bodies. In addition to robustness to significant external events, new nuclear facilities must be designed and managed to ensure their effectiveness in the following aspects: independence and reliability of the various levels of containment; Capacity 
and safety of external sources of energy, to act in case of emergency; Reliability in reactor core cooling systems [10]

\subsection{Risk-informed Decision Making in Nuclear Reactor Licensing}

Currently, regulatory bodies in several countries require the joint use of deterministic and probabilistic methods for the nuclear and environmental licensing of nuclear reactors. This process is called Risk-informed Decision Making in nuclear reactor licensing and considers several decision factors: knowledge obtained through deterministic safety analysis; principles of defense in depth; probabilistic assessment; legal requirements; and other aspects, as shown in Figure 4 [19].

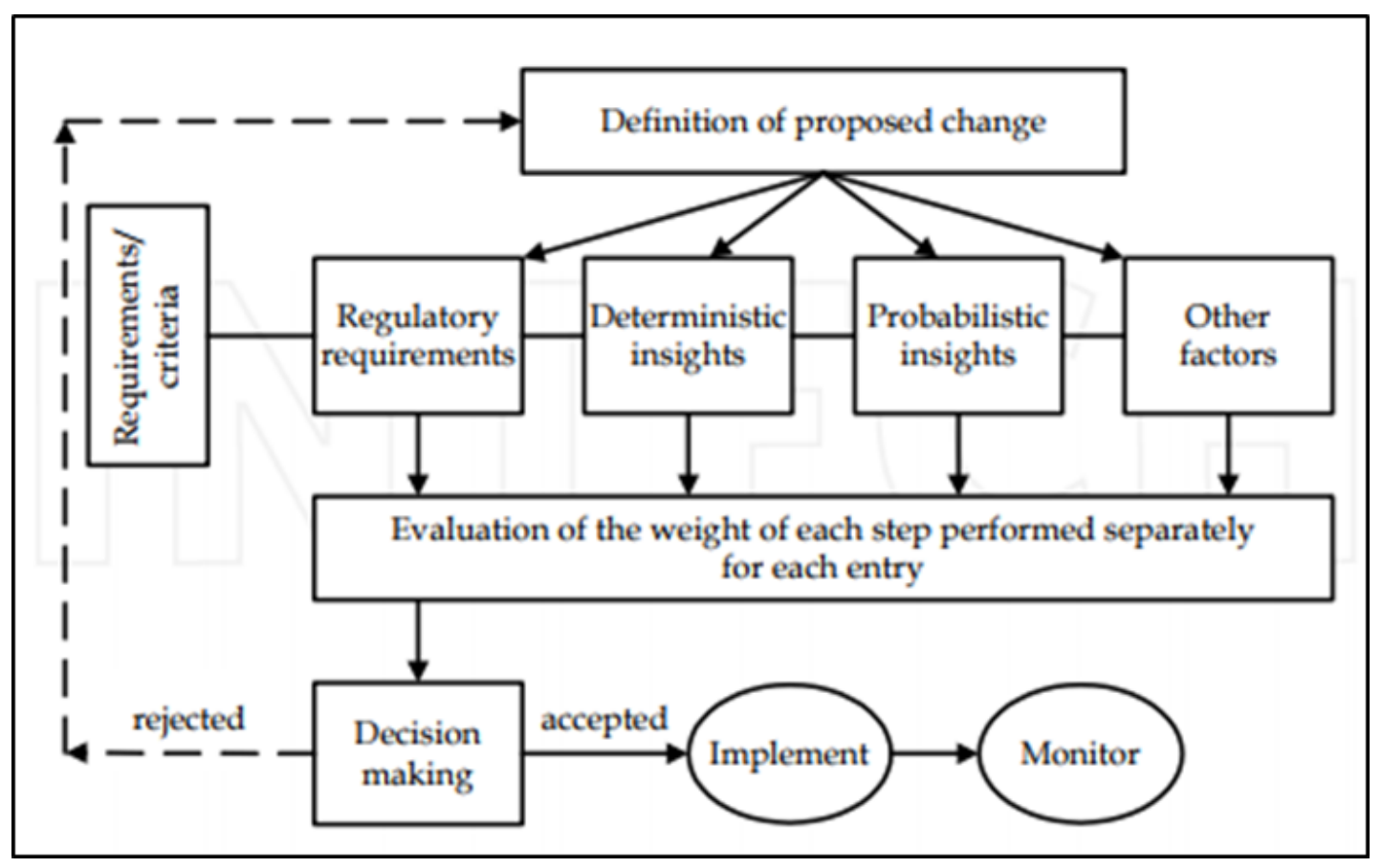

Figure 4: Principles of Risk Informed Decision Making. Source: Frutuoso e Melo et al. (2019) [19]

In order to guide the management of a nuclear power plant to ensure safe performances in all activities, it is necessary to implement safety objectives. The safety objectives are defined criteria for nuclear plants, which establish parameters of "unacceptable risk", that is, limit values from which there are no safe conditions for operation. These objectives may consist of: design features 
and standards; safe operating margins; deterministic and probabilistic calculations; and safe parameters for on-site activities [20].

When it comes to non-numerical requirements, they are called qualitative safety objectives. If they prescribe limit values to guarantee safety to workers and the external public, they are called quantitative objectives, providing parameters such as in-depth defense, dose limits and other principles. In these two modalities, they are objectives related to the DBA, and therefore involve deterministic studies. However, when they translate into frequencies of occurrence of unwanted events related to severe accidents in nuclear reactors, they consist of probabilistic safety objectives and necessarily refer to BDBAs, involving complex probabilistic studies for their definition. This category includes the following parameters: CDF; LRF; and LERF [20].

Usually, these objectives are defined at the governmental level, being managed by the companies licensed and controlled, strictly, by the regulatory agencies of each country. In the case of countries that practice the Risk-informed Decision Making, probabilistic safety objectives are important tools for ensuring the safety of nuclear reactors against the risk of severe accidents.

The consolidation of the RIDM methodology in the USA, within the scope of government agencies linked to the nuclear sector, is notorious and very important. Thanks to this philosophy, there are recent initiatives for the modernization of the U.S. Nuclear Regulatory Commission (NRC). In the meantime, new organizational processes and tools are being developed in order to optimize safety risk assessments, as well as enabling an adequate systematization of the nuclear reactor licensing processes. Some central objectives of these implementations can be mentioned: to define and use safety-related insights, in order to guide the guarantee evaluations in the implementation of the PSA; focus team resources and experience on the most important safety aspects during nuclear power plant licensing warranty reviews; recognition of new technologies, safer and more efficient than existing technologies; understand that the operational experience and the previous database cannot be neglected, otherwise failures will occur that compromise the safety of the nuclear enterprise [21].

Therefore, the PSA is a fundamental instrument in this approach, since it considers the careful analysis of the deterministic and probabilistic aspects concerning the phases of design, construction, operation and decommissioning of the nuclear reactors. In countries where the nuclear power matrix is consolidated, such as the United States of America (USA), France, the United Kingdom (UK) and 
Canada, PSA is an essential document in the licensing phases of nuclear reactors. In the next topic, a brief comparison will be presented between these countries and Brazil, regarding the use of PSA for the licensing of their nuclear power plants.

This comparison is based on an extensive bibliographic research developed by the author during his undergraduate studies at master degree. In this work, qualitative information will be presented, in order to demonstrate the objectives initially outlined.

\subsection{Comparative Performance in Relation to the Use of PSA}

The performance of the selected countries in relation to the effective use of PSA was analyzed in the following aspects: safety objectives and the Risk-informed Decision Making; procedures and the operational experience of PSA.

\section{$\underline{\text { Safety Objectives and Risk-informed Decision Making }}$}

Table 1 shows the existence or absence of safety objectives in each country, as well as whether these countries adopt the Risk-informed Decision Making as a guideline for regulating the licensing of nuclear reactors [22].

Table 1: Safety Objectives and the Risk Informed Decision Making.

\begin{tabular}{ccccc}
\hline Country & $\begin{array}{c}\text { Qualitative } \\
\text { Safety } \\
\text { Objectives }\end{array}$ & $\begin{array}{c}\text { Quantitative } \\
\text { Safety } \\
\text { Objectives }\end{array}$ & $\begin{array}{c}\text { Probabilistic } \\
\text { Safety } \\
\text { Objectives }\end{array}$ & $\begin{array}{c}\text { Risk-informed } \\
\text { Decision Making }\end{array}$ \\
\hline Brazil & $\mathrm{X}$ & $\mathrm{X}$ & - & - \\
EUA & $\mathrm{X}$ & $\mathrm{X}$ & $\mathrm{X}$ & $\mathrm{X}$ \\
UK & $\mathrm{X}$ & $\mathrm{X}$ & $\mathrm{X}$ & $\mathrm{X}$ \\
France & $\mathrm{X}$ & $\mathrm{X}$ & $\mathrm{X}$ & $\begin{array}{c}\text { Deterministic } \\
\text { official approach } \\
\text { Canada }\end{array}$ \\
\hline
\end{tabular}

Some observations from this analysis can be made. In Brazil, the regulatory body has set qualitative and quantitative safety objectives for the safety of people regarding radiological exposure without considering probabilistic safety objectives in their procedures. It is noted that the 
licensing approach of Brazilian nuclear reactors is essentially deterministic. In this way, the national legislation does not consider the Risk-informed Decision Making in its requirements.

It is also noted that all other countries surveyed adopt probabilistic safety objectives in the management of safety risks for nuclear reactors. France, although not formally adopting the Risk Informed Decision Making, has continuously improved the use of PSA as a complementary methodology to deterministic approaches.

\section{Procedures and the operational experience of PSA}

Table 02 presents an overview of the use of APS in several aspects, thus allowing a qualitative assessment of the performance of each country in relation to the application and improvement of probabilistic methodologies for nuclear reactors [22].

Table 2: Procedures and the operational experience of PSA.

\begin{tabular}{cccccc}
\hline $\begin{array}{c}\text { Aspects addressed in } \\
\text { APS }\end{array}$ & Brazil & EUA & UK & France & Canada \\
\hline $\begin{array}{c}\text { Basic guidelines and } \\
\text { procedures }\end{array}$ & $\mathrm{X}$ & $\mathrm{X}$ & $\mathrm{X}$ & $\mathrm{X}$ & $\mathrm{X}$ \\
$\begin{array}{c}\text { PSA for environmental } \\
\text { risk assessment }\end{array}$ & & $\mathrm{X}$ & & & \\
$\begin{array}{c}\text { Systematic study of PSA } \\
\text { Vulnerability assessment }\end{array}$ & $\mathrm{X}$ & $\mathrm{X}$ & $\mathrm{X}$ & $\mathrm{X}$ \\
Performance assessment & $\mathrm{X}$ & $\mathrm{X}$ & $\mathrm{X}$ & $\mathrm{X}$ \\
Periodic inspections and & $\mathrm{X}$ & $\mathrm{X}$ & $\mathrm{X}$ & $\mathrm{X}$ \\
$\begin{array}{r}\text { reviews } \\
\text { Standartization }\end{array}$ & & $\mathrm{X}$ & $\mathrm{X}$ & $\mathrm{X}$ & $\mathrm{X}$ \\
\hline & $\mathrm{X}$ & $\mathrm{X}$ & $\mathrm{X}$ & $\mathrm{X}$ \\
\hline
\end{tabular}

It may be noted that all the countries surveyed have guidelines and procedures for the use of PSA in the assessment of risks in nuclear reactors. It is noteworthy that the United States developed specific standards for environmental risk studies through PSA, unlike the other countries. In the case of Brazil, there are recent resolutions that place, as a mandatory requirement, the PSA study for the Angra 3 nuclear power plant, in the construction phase. 
Regarding the practical use of PSA (individual reactor evaluations, vulnerability study, performance measurement, inspections and standardization), there is no recent evidence for Brazilian nuclear power plants. The other countries have shown great progress in these issues.

It is emphasized that the effective application of PSA in nuclear reactor licensing processes contributes to the improvement of safety culture. This is supported by the fact that PSA requires greater rigor on the part of the whole team on safety issues in both DBA and BDBA situations. In Brazil, the guidelines for the use of PSA are very recent, requiring a few years in order to improve this methodology, and the consequent gains in safety culture.

\section{CONCLUSION}

The four countries selected for comparison with Brazil (USA, UK, France and Canada) definitively demonstrate the importance of PSA for the management of risks inherent to nuclear power plants, using such methodology in a complementary way to traditional deterministic techniques. It can be stated that the growth of the use of PSA in these four countries has been continuous, having procedures consolidated and constantly improving.

In the universe surveyed, the only countries that did not officially adopt the Risk-informed Decision Making are Brazil and France. However, it is noted that France has consistently used PSA as a complementary methodology to deterministic approaches to risk management in nuclear reactors.

It was verified that the USA has a more comprehensive and efficient management of the PSA methodology, when compared to the other countries studied. On the other hand, in Brazil there is still no systematic application of PSA techniques for the licensing of its nuclear reactors. It is expected that, from the implementation of PSA studies in the construction phase of the Angra 3 nuclear power plant, this scenario will change and Brazil will adopt PSA as a vigorous safety assurance tool in the operation of nuclear reactors. 


\section{ACKNOWLEDGMENT}

The following institutions supported this work: Nuclear Technology Development Center (CDTN), Brazilian Nuclear Energy Commission (Cnen), Research Support Foundation of the State of Minas Gerais (Fapemig) and Brazilian Council for Scientific and Technological Development $(\mathrm{CNPq})$.

\section{REFERENCES}

[1] OECD NEA - Organization for Economic Co-operation and Development / Nuclear Energy Agency. Five Years after the Fukushima Daiichi Accident: Nuclear Safety Improvements and Lessons Learnt. Paris. 2016.

[2] KUROKAWA, K. The Fukushima Nuclear Accident Independent Investigation Commission : official repport. The National Diet of Japan : Tokyo, 2012.

[3] GISQUET, E. ; OLDER, M. A Human and Organizational Factors Perspective on the Fukushima Nuclear Accident. IRSN - Institut de Radioprotection et de Sûreté Nucléaire. Rapport PSN-SRDS/SFOHREX n²015-01. April of 2015.

[4] ŠIMIĆ, Z.; MIKULIČIĆ, V.; VUKOVIĆ, I. Risk from Nuclear Power Utilization after Fukushima Accident, In: SYMPOSIUM DEVELOPMENT OF POWER ENGINEERING IN CROATIA, Faculty of Electrical Engineering, Osijek, Croatia, 2011.

[5] NRC - Nuclear Regulatory Commission. NRC: Full - Text Glossary. USA. Available at: <http://www.nrc.gov/reading-rm/basic-ref/glossary/full-text.html>. Last accessed: 10 Jul. 2019.

[6] IAEA - International Atomic Energy Agency. IAEA Safety Glossary: Terminology used in Nuclear Safety and Radiation Protection. Final Revision. Vienna. 2016.

[7] NUSBAUMER, O. P. M. Introduction to Probabilistic Safety Assessment. Available at: <http://nusbaumer.tripod.com/resources/publications/nusbaumer_introduction_to_probabilistic _safety_assessments.pdf>. Last accessed: 15 Aug. 2018. 
[8] NRC - Nuclear Regulatory Commission. Probabilistic Risk Assessment (PRA). USA, Available at: <https://www.nrc.gov/about-nrc/regulatory/risk-informed/pra.html>. Last accessed: 05 Jul. 2019.

[9] IAEA - International Atomic Energy Agency. Development and Application of Level 1 Probabilistic Safety Assessment for Nuclear Power Plants. Specific Safety Guide: Safety Standards Series No. SSG-3. Vienna, Austria, 2010.

[10]IAEA - International Atomic Energy Agency. Safety Reassessment for Nuclear Fuel Cycle Facilities in Light of the Accident at the Fukushima Daiichi Nuclear Power Plant. Safety Reports Series No. 90. Vienna. 2016.

[11]FABER, M. H. Logical Trees in Risk Analysis - an Introduction. Swiss Federal Institute of Technology. Switzerland. Available at: <http://km.fgg.uni-lj.si/PREDMETI/ovrs/ Zanesljivost/LogicalTreesInRiskAnalysis.pdf>. Last accessed: 10 Jun. 2019.

[12]KIM, D. S.; HAN, S. H.; PARK, J. H.; LIM, H. G.; KIM, J. H. Multi-unit Level 1 probabilistic safety assessment: Approaches and their application to a six-unit nuclear power plant site. Nuclear Engineering and Technology. Korean Nuclear Society, Published by Elsevier Korea LLC. 2018.

[13]IAEA - International Atomic Energy Agency. Development and Application of Level 2 Probabilistic Safety Assessment for Nuclear Power Plants. Specific Safety Guide. Safety Standards Series No.SSG-4. Vienna, Austria, 2010.

[14]CALDWELL, A. Addressing Off-site Consequence Criteria Using Level 3 Probabilistic Safety Assessment: A Review of Methods, Criteria, and Practices. Master of Science Thesis. Department of Nuclear Power Safety. KTH Royal Institute of Technology. Stockholm, Sweden, 2012. Available at: <http://www.divaportal.org/smash/get/diva2:526244/FULLTEXT01.pdf>. Last accessed: 10 Jun. 2019.

[15]SAMPAIO, P. A. B.; JUNIOR, M. A. G.; LAPA, C. M. F. A CFD Approach to the Atmospheric Dispersion of Radionuclides in the Vicinity of NPPS. 2007 International Nuclear Atlantic Conference - INAC 2007. ASSOCIAÇÃO BRASILEIRA DE ENERGIA NUCLEAR - ABEN. Brazil: Santos, 2007.

[16]NICOLICI, C.; PRISECARU, I.; NICOLICI, S.; MUSA, A. Atmospheric Dispersion of Radionuclides During a NPP Accident. Gaussian Puff vs. CFD Lagrange Particle 
Tracking. Conference: The $6^{\text {th }}$ Annual International Conference on Sustainable Development through Nuclear Research and Education. December, 2012.

[17]NRC - Nuclear Regulatory Commission. Generic Environmental Impact Statement for License Renewal of Nuclear Plants. NUREG/CR -1437. Vol. 1. Washington, DC, USA, 2013.

[18]GUEZZI, C. R.; CRAVERO, W.; FORNILLO, N. S.; The Fukushima Disaster: A Cold Analysis. Current Research in Nuclear Reactor Technology in Brazil and Worldwide. Amir Z. Mesquita (Ed.). First edition. In Tech. v. 1. p. 303-336, 2013.

[19]FRUTUOSO E MELO, P. F.; OLIVEIRA, I. M. S.; SALDANHA, P. L. LWR Safety Analysis and Licensing and Implications for Advanced Reactors. Nuclear Power - Operation, Safety and Environment. Chapter 3. v. 1. p. 47-70. In: Dr. Pavel Tsvetkov (Ed.). In Tech - Open Access Publisher. Available at: <https://cdn.intechopen.com/pdfs-wm/17967.pdf>. Last accessed: 05 Jul. 2019.

[20]IAEA - International Atomic Energy Agency. Applications of probabilistic safety assessment (PSA) for nuclear power plants. TECDOC-1200. Vienna, Austria, 2001.

[21]NRC. U.S. Nuclear Regulatory Commission. Achieving Modern Risk-Informed Regulation. SECY-18-0060. Policy Issue. 2018.

[22]MATA, J.F.C. The Role of Probabilistic Safety Analysis Methodologies in the Licensing Process for Nuclear Reactors. Master of Science Thesis. Nuclear Technology Development Center/Brazilian Nuclear Energy Commission (CDTN/(Cnen). Belo Horizonte. 2016. (in Portuguese). 